Elvira E. Symanyuk, Anna A. Pecherkina

Russia

\title{
A Study on the Components of Teachers' Professional Competence
}

DOI: 10.15804/tner.2016.44.2.16

\begin{abstract}
The aim of this research was to study the activity-related, personality-related and socio-communicative components of school teachers' professional competence. The survey of 380 teachers using standardised questionnaires identified the manifestation specificities of the components, depending on the work in conventional or innovative schools and the length of work experience.

Significant differences were found between teachers working in innovative and conventional schools. The length of work experience was found to condition the differences between the activity-related and the personality-related components.

The results obtained showed that teachers in innovative schools focus on professional development and achieving independence and are optimistic and tolerant of uncertainty. Those from conventional schools tend to strive for stable working conditions and demonstrate high anxiety levels and rigidity.
\end{abstract}

Keywords: competence, teachers' professional competence, innovative school, conventional school

\section{Introduction}

Schools, especially today, are to carry out their basic functions, "taking into consideration the challenges of our times, such as multicultural co-existence, the dominance of technology, the evolution of the sciences and the rapid renewal of 
knowledge. At the same time, schools aim at preparing students not only for the present, but also for the ever-changing future" (Liakopoulou, 2011).

In light of the abovementioned, the requirements for teachers are changing. Today, the education system is in need of an active and mobile teacher, able to use their initiative, clearly aware of their professional goals, open to everything new and optimistic about innovation (Symanyuk, Pecherkina, 2010).

\section{Research Problem}

Some researchers believe that the concept of professional competence can apply to the teaching context (Goodman et al., 2008; Oser, Achtenhagen, Renold, 2006; Tannenbaum, Rosenfeld, 1994).

As part of a broader perception of the term, a holistic approach was adopted (Ingvarson, 1998), according to which competence involves teachers' individual qualities and attitudes, as well as the skills and knowledge that result from their work.

In Europe, teachers' professional competences were defined in various working groups and committees that drafted the «Common European Principles for Teacher Competences and Qualifications» (Memorandum, 2005; Commission of the European Communities, 2007).

A number of competences were identified, based on three main dimensions of teachers' work: human beings, knowledge and society. The teacher's task was described as follows: working with others, working with knowledge, technology and information, and working with and in society (Hannele Niemi, 2012).

Most researchers define professional competence as the skills and qualities of a highly professional employee, who is capable of realising themselves in specific types of work, is able to adapt to the changing conditions of the market mechanism, and who can manage their professional mobility and professional self-regulation.

In Russia, the term "professional competence" has no shared understanding yet.

The structural components of teachers' professional competence are determined through a hierarchy of knowledge, skills and personal qualities (N.V. Andronova, T.V. Dobudko, E.G. Islamgaliev, A.G. Kazakova, L.V. Komarovskaya, N.V. Kuzmina, V.A. Slastenin, etc.); through a number of specific skills that are associated with mastery of the profession (Y.V. Vardanyan, A.K. Markova, N.V. Matyash, E.M. Pavlyuchenkov, etc.); and through specific components: motivational, cognitive, personal, reflective, etc. (I.V. Grishina, N.E. Kostyleva, 
I.O. Kotlyarova, and others) (Andronova, 2000, Kuzmina, 1985, Kostyleva, 1997, Markova, 1980, Mitina, 1995).

In this study, the teacher's professional competence is viewed as the integration of the activity-related, personality-related, and the socio-communicative components that ensure the implementation of the educational program.

The activity-related component of teachers' professional competence includes subject and activity-related knowledge, the desire to be a professional, the aspiration for the freedom of choice, orientation towards working with people, towards the integration of the efforts of others, the desire to create something new, the willingness to overcome obstacles and to take responsibility for the result, the motivation to achieve success, and the willingness to take risks.

The personality-related component of teachers' professional competence is represented by the desire to build one's own life, to take responsibility for events taking place in it, the ability to offer support, to help others, the commitment to self-development, and the ability to control one's emotional states.

The socio-communicative component of teachers' professional competence manifests itself in flexibility in communication, tolerance of uncertainty, optimism, and well-developed self-control in communication.

The presented study shows the results of an investigation into the activity-related, personality-related and socio-communicative components of teachers' professional competence, depending on the type of school they work in (conventional and innovative) and the length of work experience.

\section{Research Focus}

The research focuses on examining the structural components of teachers' professional competence, depending on what type of school the teachers work in - conventional or innovative.

A conventional school is characterised by relative stability aimed at maintaining the established order, the focus is on the educational process.

A 'search mode' is typical of an innovative school, aimed at forming a new education content, developing and introducing new educational technologies, creating new types of educational institutions.

The scientific relevance of the research results is as follows:

- the structural components of teachers' professional competence were identified; 
- the differences in the manifestation of the activity-related, personality-related and socio-communicative components of professional competence were revealed;

- the activity-related and personality-related components of the professional competence were found to change in correlation with the increase in the length of teaching experience;

- the relationship between the indicators of the professional competence components was discovered to depend on the conditions of the educational environment.

The study has broad practical implications - the research results can be used to develop educational programs for future teachers, to carry out teachers' certification, as well as to provide psychological and pedagogical support for the professional development of in-service teachers.

\section{$\underline{\text { Research Methodology }}$}

\section{Research General Background}

The problem has become relevant in view of adopting professional standards for teachers, which emphasizes the need to identify the requirements for teachers' personal and professional qualities, their professional activity, and the level of their professional competence (Professional Standard “Teacher").

The purpose of the research was to study the structure of teachers' professional competence in innovative and conventional schools.

The study is based on the following assumptions:

- The structural components of teachers' professional competence are likely to have more complex and integrated relationships in innovative schools.

- The degree of development of the activity-related, personality-related and socio-communicative components of the teacher's professional competence is likely to depend on the length of teaching experience.

An experimentally designed correlation study was used to compare the nature of significant correlations between the examined parameters in nonequivalent groups: 1) teachers working in conventional schools and teachers working in traditional schools; and 2) groups of teachers with different length of teaching experience.

The study was carried out individually and anonymously with every teacher receiving a pack of questionnaires. 


\section{Research Sample}

The survey included 380 secondary school teachers from Yekaterinburg, Russia. All the respondents were women aged from 22 to 70 . Table 1 gives the detailed description of the survey participants.

Table 1. Characteristics of research participants, depending on the educational environment conditions, $\%$

\begin{tabular}{|c|c|c|}
\hline $\begin{array}{l}\text { Innovative educational } \\
\text { environment conditions }\end{array}$ & $\begin{array}{l}\text { Teachers working } \\
\text { in conventional schools } \\
(\mathrm{n}=195)\end{array}$ & $\begin{array}{l}\text { Teachers working } \\
\text { in innovative schools } \\
(n=185)\end{array}$ \\
\hline Teachers' Rank ('category') & $\begin{array}{l}\text { Highest 'category' - } 15 \\
\text { First 'category' - } 48 \\
\text { Second 'category' - } 29 \\
\text { No 'category' - } 8\end{array}$ & $\begin{array}{l}\text { Highest 'category' - } 53 \\
\text { First 'category' - } 32 \\
\text { Second 'category' - } 14 \\
\text { No 'category' - 1 }\end{array}$ \\
\hline $\begin{array}{l}\text { Use of innovative technologies } \\
\text { in the educational process }\end{array}$ & 46 & 83 \\
\hline In-service Training & $\begin{array}{l}\text { Several times during the aca- } \\
\text { demic year }-12 \\
\text { Once a year - } 24 \\
\text { Once in three years - } 22 \\
\text { Once in } 5 \text { years }-42\end{array}$ & $\begin{array}{l}\text { Several times during the aca- } \\
\text { demic year - } 37 \\
\text { Once a year - } 29 \\
\text { Once in three years - } 28 \\
\text { Once in } 5 \text { years - } 6\end{array}$ \\
\hline
\end{tabular}

\section{Instrument and Procedures}

The following standardised questionnaires were used as research tools:

- to study the activity-related component of the teachers' professional competence - career orientations diagnosing technique by E. Schein (including questions on such scales as "professional competence", "management", "autonomy (independence)", "stability", "service/dedication", "challenge”, "lifestyles integration", "entrepreneurial creativity"); method of determining the motivation to succeed by T. Ehlers (a mono-scale questionnaire that includes 41 questions); method of determining the motivation for avoiding failure by T. Ehlers (a mono-scale technique involving assessing a 30-line word list with 3 words in each line);

- to study the personality-related component of the teachers' professional competence - a test of life orientations by D.A. Leontiev (involving evaluation of 20 pairs of opposing statements on the scales of "life purpose", "life process", "life result", "locus of control - I", "locus of control - life" and 
overall indicator - "meaningfulness of life"); self-assessment checklist of emotional states by $\mathrm{H}$. Eysenck (including questions on the scales of "anxiety", "aggressiveness", "frustration", "rigidity"); a questionnaire to evaluate the level of empathy by A. Mehrabian (a mono-scale questionnaire including 25 questions);

- to study the socio-communicative component of the teachers' professional competence - a questionnaire to assess the socio-communicative competence (including such scales as "socio - communicative adaptability", "desire for consensus," “tolerance," "optimism," "frustration tolerance").

\section{Data Analysis}

The data collected from the survey were analysed using the "Statistical Package for Social Sciences" (SPSS).

To determine the originality of the relationship between the indicators of professional competence, the Spearman correlation analysis was used. In order to determine the reliability of the differences in the manifestation of professional competence indicators in the teachers working in conventional and innovative schools and those with different length of teaching experience, the Mann-Whitney U-test was used.

\section{Research Results}

\section{Results of descriptive statistics of the teachers' professional competence indicators}

According to the analysis of the average values, the activity-related component of the teachers' professional competence in innovative schools is characterised by the predominance of motivation for success (66.7\%). Also, the teachers aim to become professionals (30.5\%), to have freedom of choice (27.2\%). For them, the situation of competition, innovation and diversity has a great value (25\%). The teachers working in conventional schools demonstrate high and very high levels of motivation for avoiding failure (61.2\%), and the desire for freedom from rules, regulations and restrictions (25.7\%). The orientation towards taking responsibility for the outcome of their work, the desire to organise (let alone, to control) the space of others is the least manifested (11.2\%), as well as the aspiration to overcome difficulties on the way to achieving a goal (9.7\%). The level of subject 
and activity-related knowledge correlates with the qualifying characteristics that determine the teachers' rank. The teachers with higher qualification ranks prevail in innovative schools.

The personality-related component of the teachers' professional competence in innovative schools showed the prevalence of low levels of performance anxiety (58.3\%), frustration (72.2\%), aggression (52.7\%) and rigidity (58.3\%). The teachers demonstrate the presence of meaning and purpose in life $\left(\mathrm{X}_{\text {average }}=38\right)$, the perception of life as an emotionally intense and interesting one $\left(\mathrm{X}_{\text {average }}=37\right)$, a marked desire to control their lives, make their own decisions and implement them $\left(\mathrm{X}_{\text {average }}=33.9\right)$. The teachers working in conventional schools demonstrate a tendency to worry and anxiety (57.2\%), as well as attachment to familiar well-rehearsed actions (68.6\%). They do not attach much importance to memories of the past and do not demonstrate focus on the future $\left(\mathrm{X}_{\text {average }}=34.2\right)$.

The socio-communicative component of the teachers' professional competence in innovative schools is characterised by flexibility in communication $(52.7 \%)$, by the ability to defend their point of view (61.2\%), tolerance for the views and actions of others $(55.5 \%)$, cheerfulness and optimism (75\%). The teachers in conventional schools are distinguished by ease of establishing contact with different people (of different age, education level, social status, etc.), by the ability to negotiate $(80.2 \%)$, by the lack of willingness to take responsibility $(88.5 \%)$, and by distrust and skepticism (85.7\%)

\section{Results of comparative analysis of the teachers' professional competence components indicators}

The teachers working in innovative schools have higher levels of career orientations manifestation - such indicators as «management» $(\mathrm{U}=414.5 ; \mathrm{p}=0.013)$, «challenge» $(U=423 ; p=0.023)$, «entrepreneurship» $(U=413 ; p=0.012)$, and locus of control indicators: «I» $(\mathrm{U}=462.5 ; \mathrm{p}=0.053)$, «empathy» $(\mathrm{U}=422 ; \mathrm{p}=$ $0.016)$, «effective empathy» $(U=408 ; p=0.010)$, «tolerance of uncertainty» $(U=$ $355.5 ; \mathrm{p}=0.002)$ and «optimism» $(\mathrm{U}=433 ; \mathrm{p}=0.023)$. This result demonstrates the teachers' desire to change, their ability to manage their own lives and actions of others, the ability to understand, to assist and support people around, tolerance and positive attitude towards the occurring events.

The teachers working in conventional schools have higher rates of anxiety $(\mathrm{U}=413 ; \mathrm{p}=0.012)$, frustration $(\mathrm{U}=433.5 ; \mathrm{p}=0.023)$ and rigidity $(\mathrm{U}=394 ; \mathrm{p}=$ 0.006). This result indicates that the teachers who work in schools where there are no innovative activities focus more on their emotions. Perhaps that is why any 
innovations cause strong emotional resistance and unwillingness to include them in their professional activities.

\section{Results of the correlation analysis of the teachers' professional competence components}

The correlation analysis allowed for detailing the overall picture (Figure 1). The greatest number of correlations between indicators of professional competence components was found in the group of teachers from innovative schools (49 statistically significant correlations), which indicates a high consistency of professional competence indicators, and justifies their belonging to the structure of professional competence as a single whole. It allows the teachers to be more flexible and mobile in mastering innovation. The basic indicators are: challenge (7 correlations), entrepreneurship ( 9 correlations), motivation for success ( 8 correlations), the meaning and purpose in life (6 relations), and socio-communicative adaptability (6 correlations). Working in conditions of innovative educational environment generates commitment and awareness of the purpose of life, the motivation to succeed, the desire to create something new, to overcome obstacles, flexibility in communication, the ability to interact with many different people, to adapt to changing circumstances, to re-evaluate events, actively find their place in the events, thus showing the orientation towards competing and winning.

In the group of teachers from conventional schools, the correlations matrix between the indicators of different components of professional competence is less dense ( 25 statistically significant correlations).

The most significant are the indicators of "rigidity" (5 correlations), "anxiety" (4 correlations), "purpose in life" (4 correlations), and "autonomy" (5 correlations). Working in a conventional school reduces flexibility, increases anxiety, and creates the desire for independence, correlation between such indicators of socio-communicative competence as "optimism", "uncertainty avoidance", "frustration tolerance", which is essential for accepting innovation. Perhaps that is why the teachers do not apply innovations in their professional activities, and demonstrate emotional resistance to innovation in general. As a result, their educational activities are mostly about reproducing actions set by appropriate regulations.

Comparison of the correlations led to the conclusion that the components of professional competence have more complex and integrated relationships in the context of educational environment conditions (the number of correlations increases from 25 to 49 ). The teachers in conventional schools are characterised by the activity-related and the personality-related components being interconnected, 

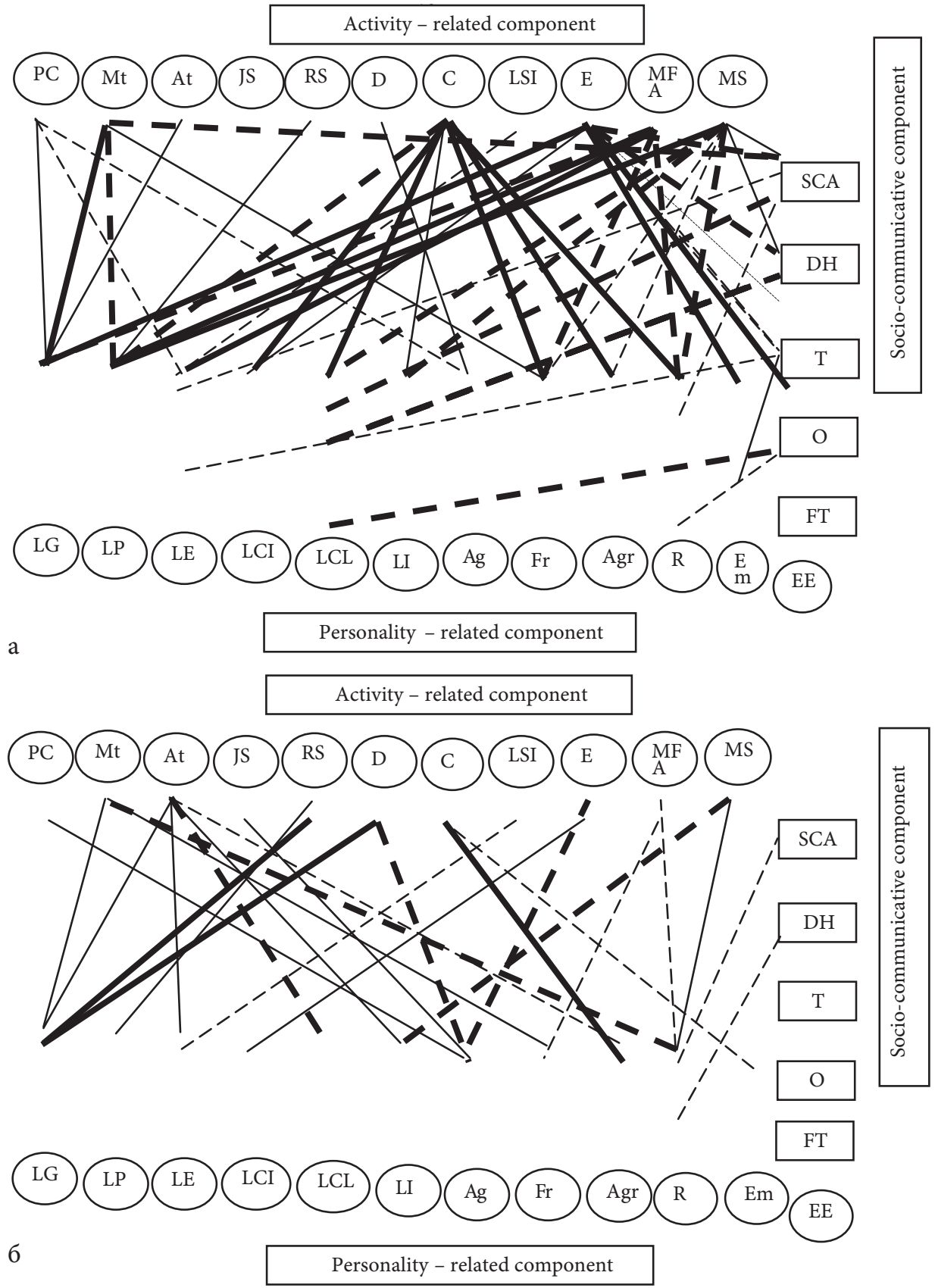

Figure 1. Correlations between indicators of professional competence components in teachers from innovative schools (a) and those from conventional schools (b) 
Figure 1: Legend:

Captions:

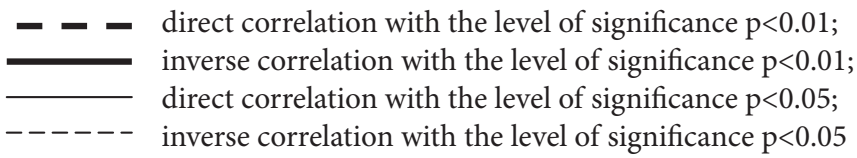

PC - professional competence; Mt - management; At - autonomy; JS - job security; RS - residence/ accomodation security; D - dedication; C - challenge; LSI - life style integration; E - entrepreneurship; MS - motivation for success; MFA - motivation for avoiding failure; LG - goals in life; LP - process of life; LE - life effectiveness; LCI - locus of control 'I'; LCL - locus of control 'life'; LI - overall life orientations; Ag- anxiety; Fr - frustration; Agr - aggressiveness; R - rigidity; Em empathy; EE - effective empathy; SCA - socio-communicative adaptability; DH - desire for harmony; $\mathrm{T}$ - tolerance; $\mathrm{O}$ - optimism; FT - frustration tolerance.

and the teachers working in innovative schools - by the activity-related, personality-related and socio-communicative components interconnection.

Thus, the hypothesis that the degree of manifestation of professional competence components indicators depends on the conditions of the educational environment was confirmed.

\section{Results of comparative analysis of professional competence indicators in teachers with different length of teaching experience}

For the second phase of hypothesis testing, the sample was divided into 5 groups according to the length of teaching experience: $1^{\text {st }}$ group - up to 5 years of teaching; $2^{\text {nd }}$ group -6 to 10 years; $3^{\text {rd }}$ group -11 to 15 years; $4^{\text {th }}$ group -16 to 25 years; $5^{\text {th }}$ group - over 25 years. This distribution is due to the fact that, first, the frequency of the teachers' performance appraisal is connected with the certification procedures; secondly, it is optimal for quantitative and qualitative analysis using statistical methods.

In the process of studying the nature of differences in the values of the indicators of the teachers' professional competence components in the teachers with different experience we found that there are significant differences between the activity-related and personality-related components.

The teachers with up to 5-year experience demonstrate a marked desire to work with people, to help people, the desire to make the world better $(\mathrm{U}=10.0 ; \mathrm{p}=$ 0.031). With increasing length of teaching experience (6 to 10 years), the teachers working in innovative schools demonstrate an increase in the interest in life and 
its emotional intensity $(\mathrm{U}=6.0 ; \mathrm{p}=0.007)$, satisfaction with self-realisation $(\mathrm{U}=$ $12.50 ; \mathrm{p}=0.050)$, they see themselves as a successful person with sufficient freedom of choice to build a life in accordance with their own objectives $(U=8.050$; $p$ $=0.015)$. In the group of teachers from conventional schools, there is an increase in rigidity $(\mathrm{U}=8.0 ; \mathrm{p}=0.032)$, anxiety $(\mathrm{U}=5.0 ; \mathrm{p}=0.008)$, and motivation for avoiding failure $(\mathrm{U}=9.0 ; \mathrm{p}=0.033)$.

In the group of teachers with the experience of 11 to 15 years of working in innovative schools, higher levels of motivation to achieve success $(U=80.50$; $\mathrm{p}=0.033)$ and anxiety $(\mathrm{U}=55.50 ; \mathrm{p}=0.012)$ were identified. In the group of teachers from traditional schools, anxiety $(\mathrm{U}=11.0 ; \mathrm{p}=0.009)$ and rigidity $(\mathrm{U}=$ $4.5 ; \mathrm{p}=0.006$ ) continue to increase, accompanied by a reduction in the degree of manifestation of ideas about oneself as a successful person $(U=8.0 ; p=0.030)$.

No meaningful significant differences were found between the groups of teachers with 11-15-year experience and those with 16-25-year experience; this may be due to the fact that at this stage of professionalisation in the development of the professional competence there is no significant change as the teacher reaches stable performance.

In the group of teachers from innovative schools with over 25 years of experience, there is an increase in the value of such indicators as "autonomy" ( $\mathrm{U}=$ $380, p=0.015)$, "entrepreneurship" $(U=382, p=0.016)$, and a reduction in the aggressiveness degree $(\mathrm{U}=407 ; \mathrm{p}=0.035)$, which is manifested in the actualisation of the desire for independence, taking responsibility for the final result, and the desire to create something new. In the group of teachers from conventional schools, a decrease is observed in the orientation towards integrating the efforts of others $(\mathrm{U}=215, \mathrm{p}=0.006)$; accompanied by the increased desire to work in a stable environment $(\mathrm{U}=115, \mathrm{p}=0.037)$ on the background of pertaining rigidity $(\mathrm{U}=187 ; \mathrm{p}=0.004)$.

In terms of the socio-communicative component, no significant differences were found in any of the compared groups. Apparently, this component is not sensitive to the length of teaching experience. Perhaps this is due to the fact that the performance of professional duties in the framework of pedagogical activity requires constant communication with both the students and their parents, colleagues, and school administration. As a result, the activity itself becomes a means of developing the socio-communicative component of the teachers' professional competence.

Thus, the hypothesis that the values of the indicators of the teachers' professional competence components depends on the length of service was confirmed. 


\section{Discussion and conclusions}

The results obtained allow for the following conclusions:

1. The structure of the teachers' professional competence was identified and empirically tested.

2. The specifics of the teachers' professional competence depending on the conditions of the educational environment were identified. The teachers working in innovative schools demonstrate high degrees of career orientations, as well as high values of such indicators as "locus of control - I", "empathy", "effective empathy", "uncertainty avoidance" and "optimism". High levels of anxiety, frustration and rigidity are typical of the teachers from conventional schools.

3. With the length of teaching experience in innovative schools increasing, the interests in life become more specified, the self-perception as a successful person is formed, the emotional richness of life increases, and the desire for professional self-development and independence becomes more urgent. In the group of teachers from innovative schools, there is a decrease in orientation towards integrating the efforts of others, an increase in the desire to work in a stable environment, in rigidity and anxiety levels.

The presented research is not exhaustive in terms of exploring the problem of developing the teacher's professional competence and can be continued to study its peculiarities depending on the type of the educational institution and the subject taught (human or technical sciences).

\section{References}

Andronova, N. (2000). The ability to devise psycho-pedagogical recommendations as a component of a teacher's professional competence (Candidate of Science dissertation). Russia, Kazan.

Commission of the European Communities (2007). Improving the Quality of Teacher Education. Communication from the commission to the Council and the European parliament 3.8.2007. Brussels: Directorate-General for Education and Culture. Retrieved 15/08/2015, from http://ec.europa.eu/education/com392_en.pdf.

Goodman, G., \& Arbona, C., \& Dominguez de Rameriz, R. (2008). High stakes, minimum-competency exams: How competent are they for evaluating teacher competence? Journal of Teacher Education, 59, 24-39.

Hannele, N. (2012). Relationships of Teachers' Professional Competences, Active Learning and Research Studies in Teacher Education in Finland. Reflecting Education. Vol 8, No. 2, December 2012, 23-44.

Ingvarson, L. (1998). Teaching standards: Foundations for professional development reform. 
In: A. Hargreaves, A. Leiberman, M. Fullan, \& D. Hopkins (Eds.), International Handbook of Educational change, pp. 1006-1031. Netherlands: Kluwer Academic Publishers. Kostyleva, N.E. (1997). Psychological and pedagogical conditions for effective management of teachers' professional competence development in the process of humanizing and democratizing education (Candidate of Science dissertation). Kazan.

Kuzmina, N.V. (1985). A teacher's aptitude, natural gifts and talent. Russia, Leningrad: Znanie.

Liakopoulou, M. (2011) The Professional Competence of Teachers: Which qualities, attitudes, skills and knowledge contribute to a teacher's effectiveness? International Journal of Humanities and Social Science, Vol. 1 No. 21 [Special Issue - December 2011], 66-78.

Markova A.K. (1980). Psychological analysis of teachers' professional competence. Pedagogics, 8, 82-89.

Memorandum (2005). Common European Principles for Teacher Competences and Qualifications. The memorandum of the expert group in the field of teacher education (Prof. Sonia Blanford, UK; Prof. Bernard Cornu, France; Prof. Hannele Niemi, Finland; and Prof. Pavel Zgaga, Slovenia). Brussels: Directorate-General for Education and Culture.

Mitina, L.M. (1995). Psychology of a teacher's professional development (Doctoral dissertation). Moscow.

Oser, F.K., \& Achtenhagen, F., \& Renold, U. (Eds.). (2006). Competence oriented teacher training. Old research demands and new pathways. Rotterdam, the Netherlands: Sense.

Professional Standard “Teacher” (2013). Retrieved 15/08/2015, from http://www.ug.ru/ new_standards/6.

Symanyuk, E. \& Pecherkina, A. (2010). Counteracting Professional Deformation. National Education, 9, 265-269.

Tannenbaum, R.J., \& Rosenfeld, M. (1994). Job analysis for teacher competency testing: Identification of basic skills important for all entry level teachers. Educational and Psychological Measurement, 54, 199-211. 